\title{
A Systematic and Critical Review of Discrete Choice Experiments in Asthma and Chronic Obstructive Pulmonary Disease
}

\author{
Hannah Collacott ${ }^{1} \cdot$ Dian $_{\text {Zhang }}{ }^{2} \cdot$ Sebastian Heidenreich ${ }^{1} \cdot$ Tommi Tervonen $^{1,3}$
}

Accepted: 14 June 2021 / Published online: 12 July 2021

(c) The Author(s) 2021, corrected publication 2021

\begin{abstract}
Background Regulators have called for greater emphasis on the role of the patient voice to inform medical product development and decision making, and expert guidelines and reports for asthma and chronic obstructive pulmonary disease (COPD) both explicitly recommend the consideration of patient preferences in the management of these diseases. Discrete choice experiments (DCEs) are commonly used to quantify stakeholders' treatment preferences and estimate the trade-offs they are willing to make between outcomes such as treatment benefits and risks.

Objective The aim of this systematic literature review is to provide an up-to-date and critical review of DCEs published in asthma and COPD; specifically, we aim to evaluate the subject of preference studies conducted in asthma and COPD, what attributes have been included, stakeholders' preferences, and the consistency in reporting of instrument development, testing and reporting of results.

Methods A systematic review of published DCEs on asthma and COPD treatments was conducted using Embase, Medline and the Cochrane Database of Systematic Reviews. Studies were included if they included a DCE conducted in a relevant population (e.g. patients with asthma or COPD or their caregivers, asthma or COPD-treating clinicians, or the general population), and reported quantitative outcomes on participants' preferences. Study characteristics were summarised descriptively, and descriptive analyses of attribute categories, consistency in reporting on key criteria, and stakeholder preferences were undertaken.

Results A total of 33 eligible studies were identified, including 28 unique DCEs. The majority $(n=20 ; 71 \%)$ of studies were conducted in a patient sample. Studies focused on inhaler treatments, and included attributes in five key categories: symptoms and treatment benefits $(n=23 ; 82 \%)$, treatment convenience $(n=19 ; 68 \%)$, treatment cost $(n=17 ; 61 \%)$, treatment risks $(n=13 ; 46 \%)$, and other $(n=10 ; 36 \%)$. Symptoms and treatment benefits were the attributes most frequently ranked as important to patients $(n=26,72 \%)$, followed by treatment risks $(n=7,39 \%)$. Several studies $(n=9,32 \%)$ did not qualitatively pre-test their DCE, and a majority did not report the uncertainty in estimated outcomes $(n=18 ; 64 \%)$.

Conclusions DCEs in asthma and COPD have focused on treatment benefits and convenience, with less evidence generated on participants' risk tolerance. Quality criteria and reporting standards are needed to promote study quality and ensure consistency in reporting between studies.
\end{abstract}

\section{Key Points For Decision Makers}

Currently, discrete choice experiments in asthma and chronic obstructive pulmonary disease focus on inhaled treatments, with relatively few studies assessing prefer-

Tommi Tervonen

tommi.tervonen@evidera.com ences for symptoms, quality of life or service delivery. No studies assess preferences for biologic therapies.

Evidera, The Ark, 201 Talgarth Rd, London W6 8BJ, UK

2 Evidera, Bethesda, MD, USA

3 Department of Epidemiology, University of Groningen, University Medical Center Groningen, Groningen, The Netherlands

There is limited assessment of risk tolerance in the current literature despite patients placing importance on risk attributes when included. 


\section{Introduction}

Asthma and chronic obstructive pulmonary disease (COPD) manifest multiple symptoms that may differ among patients, and are treated with various rescue and maintenance medications. The treatment landscape in asthma and COPD has expanded in recent years with a number of new treatments and devices coming to the market $[1,2]$, which not only results in greater choice for patients and decision makers, but impacts on patients' quality of life (QoL) as well as the way in which treatment-related services and management plans are developed and delivered.

There have been calls from several relevant bodies, including clinical [3, 4], regulatory [5] and health technology assessment agencies [6-9], for a greater emphasis on the patients' voice, including patients' preferences, throughout clinical development and approval processes, and in the delivery of services. With a variety of treatments and devices available, it is particularly relevant to develop an understanding of patients' preferences in asthma and COPD, not only for clinical outcomes, but for the variety of device-related features that exist. Both the US Food and Drug Administration (FDA) and European Medicines Agency (EMA) have published guidance on the use of patient preferences in the regulatory approval process [10-12]. Patient preferences are also highlighted as key considerations for the management and prevention of asthma in the Global Initiative for Asthma report and recent 2020 Focused Updates to the Asthma Management Guidelines [3, 13], and are also mentioned in the Global Initiative for COPD report [4].

Discrete choice experiments (DCEs) are commonly used to elicit the preferences of relevant stakeholders in the health domain. The use of DCEs to elicit patients' health preferences has grown in recent years [14]. Unlike other survey techniques, DCEs estimate participants' preferences and the trade-offs they are willing to make based on responses to several choice questions. Although non-indication-specific reviews are useful for understanding how methodological and reporting standards have developed over time [14, 15], they do not inform researchers of the current state of knowledge within specific indications. A previous review of patient preference studies in asthma and COPD was conducted in 2015 [16], but it did not specifically review the DCE methodology nor report on the consistency in reporting of key study criteria or attributes included in the studies. This paper aims to provide an up-to-date and critical review of published DCEs in patients with asthma or COPD or their caregivers, asthma or COPD-treating clinicians, and the general population, including an assessment of the consistency in reporting across key criteria. Specifically, we aim to evaluate the subject of preference studies conducted in asthma and COPD, what attributes have been included, stakeholders' preferences, and the consistency in reporting of instrument development, testing and reporting of results.

\section{Methods}

\subsection{Searches}

The current systematic review focuses on DCEs published in asthma and/or COPD between 1990 and 2020. Search strings were developed by an information specialist in consultation with the study team, based on the requirements of this study and after a review of the methods of similar studies [14, 17-19]. Prior to execution, the searches were piloted to ensure known studies were identified. Searches were run in Embase, Medline and the Cochrane Database of Systematic Reviews. Duplicate results were removed prior to screening. The full search strategy is included as Electronic Supplementary Material (ESM; Table S1).

\subsection{Screening}

Screening was conducted over several phases: pilot, title/ abstract (TIAB), and full-text (FT) screening. Screening was conducted by the same two analysts (HC, DZ) at each phase, with each record double screened. Studies were included if they were conducted in the population of interest (i.e. asthma and/or COPD patients, caregivers, asthma or COPD-treating clinicians, and the general population), reported preference outcomes from a DCE or conjoint analysis (CA) task, and were published as a full-text English-language article within the review period. Studies were excluded if they were not primary research (i.e. editorial or opinion pieces) or were purely methodological in nature. Pilot screening involved double-screening of the first 50 records; decisions were compared, and any disputes were resolved by a senior researcher. Articles included at the TIAB level were then screened at the FT level. Articles included at the FT level were reviewed by a senior researcher (TT) as a final quality-control step.

\subsection{Extraction}

All studies included at the FT level were extracted into a pre-defined template. The extraction template included all key endpoints; study characteristics (e.g. indication, country, responder type and sample size), participant characteristics (e.g. age, sex, duration of disease), study design characteristics (e.g. attribute development and qualitative testing processes, attributes and levels, statistical design and analysis model) and results. Extraction was conducted by the two analysts involved at screening (HC, DZ), and was piloted with three articles to ensure consistency in extraction styles before full extraction was completed. Ten percent of studies 
were double-extracted by $\mathrm{HC}$ as a quality-control step. The study team met after extraction of the first ten articles to discuss and align on the extraction endpoints.

\subsection{Analysis}

Study characteristics, including analysis models used and the assessment of preference heterogeneity, were analysed using descriptive statistics. The preference subject of each study was extracted to determine the current focus of asthma/COPD preference literature and identify gaps in the research. Attributes across the studies were broken down into categories and subcategories with corresponding frequencies, providing an overview of the concepts for which preferences have been elicited. Overarching attribute categories were symptoms and treatment benefits, treatment risks, treatment convenience, treatment cost, and other. The relative importance of attribute categories across studies was assessed based on relative attribute importance (RAI) scores where reported; where RAI was not available, this was calculated using the coefficients. Where a study reported multiple models, results for each were included in the attribute ranking analysis.

Additionally, the extent to which studies reported on four criteria was assessed. The criteria included in this assessment were informed by existing literature and guidelines on quality steps in conducting and reporting on preference studies [10-12, 20, 21]. This assessment is intended to provide an overview of reporting practices. The criteria assessed were as follows:

1. Attribute development processes. The number of studies reporting implementation of key steps to develop the attributes and levels were counted; the steps considered included qualitative interviews or focus groups with the population of interest or consultation with clinical experts, with or without a review of the relevant literature. Such steps provide evidence on the relevance of the selected attributes and levels, with clear reporting mitigating the risk of bias in the selection process [20].

2. Instrument pre-testing processes, such as qualitative piloting. The number of studies reporting that the DCE instrument had been pre-tested in the target population through interviews or other qualitative means prior to data collection were counted. Pilot testing in this way allows researchers to test the assumptions made in the design process, as well as the completeness, relevance or complexity of the elicitation instrument [20].

3. Experimental design characteristics. The number of studies reporting on characteristics relating to the statistical design of the DCE instrument, including design type, design plan, blocking or randomisation were counted. The experimental design is used to avoid fun- damental issues such as confounding, correlation or insufficient variation, and dictates the number of tasks presented to respondents, all of which impact on the quality and validity of the resulting preference data [20].

4. Behavioural outcomes including marginal rates of substitution (MRS) or uptake probabilities, including measures of uncertainty. The number of studies reporting a behavioural outcome such as MRS, relative attribute importance, or predicted uptake probability with a measure of uncertainty of the estimate were counted. Such behavioural insights that take into account attribute trade-offs are one of the key outputs of preference research, and the underreporting of measures of uncertainty may lead to inaccurate policy advice [15].

Each study was assessed across the reporting criteria separately by two analysts (HC, DZ), with any discrepancies reviewed and resolved by a senior researcher (TT).

\section{Results}

A total of 425 studies were identified after de-duplication. After screening, 33 studies were included for extraction [15, 22-53]. The PRISMA [54] diagram in Fig. 1 outlines the flow of studies through the screening process. Four studies were excluded during screening due to having a methodological-only focus [26, 55-57]. Further, five [39, 44, 46, 51, $52]$ of the 33 included studies provided a secondary review or analysis of an existing study; such studies have not been counted twice when calculating descriptive statistics but are included in the study overview table (Table S6, see ESM). The resulting 28 full-text studies were used in the descriptive analysis.

\subsection{Study Characteristics}

An overview of the study characteristics is provided in Table 1. The trend in DCE publication over time follows that of previous reviews [14, 17-19]; only one study (4\%) was published prior to 2000 [45], while nine studies (32\%) were published during the period between 2016 and 2020. Sixteen studies (57\%) were conducted in an asthma population, nine studies in a COPD population (32\%) and three studies [29, $49,58]$ in a mixed asthma and COPD population $(11 \%)$. Studies assessed preferences across a range of subjects, most frequently inhaler treatments $(n=16,57 \%)$, followed by non-specific treatment types $(n=4,14 \%)$, symptoms and QoL [26, 37, 40], treatment and service delivery [24, 28, 48] (both $n=3,11 \%$ ), and service delivery alone [43, 53] $(n=2,7 \%)$. Service delivery was defined as concepts relating to the non-clinical administration or distribution of treatment, such as health care provider (HCP) specialisation, the 
Fig. 1 PRISMA diagram. $C A$ conjoint analysis, $C O P D$ chronic obstructive pulmonary disease, DCEs discrete choice experiment. *Synthesis and descriptive characteristics run on sample $\mathrm{n}=28$; 33 studies identified, 5 dropped from synthesis and descriptive characteristics due to reporting secondary analyses of results of an already-included study

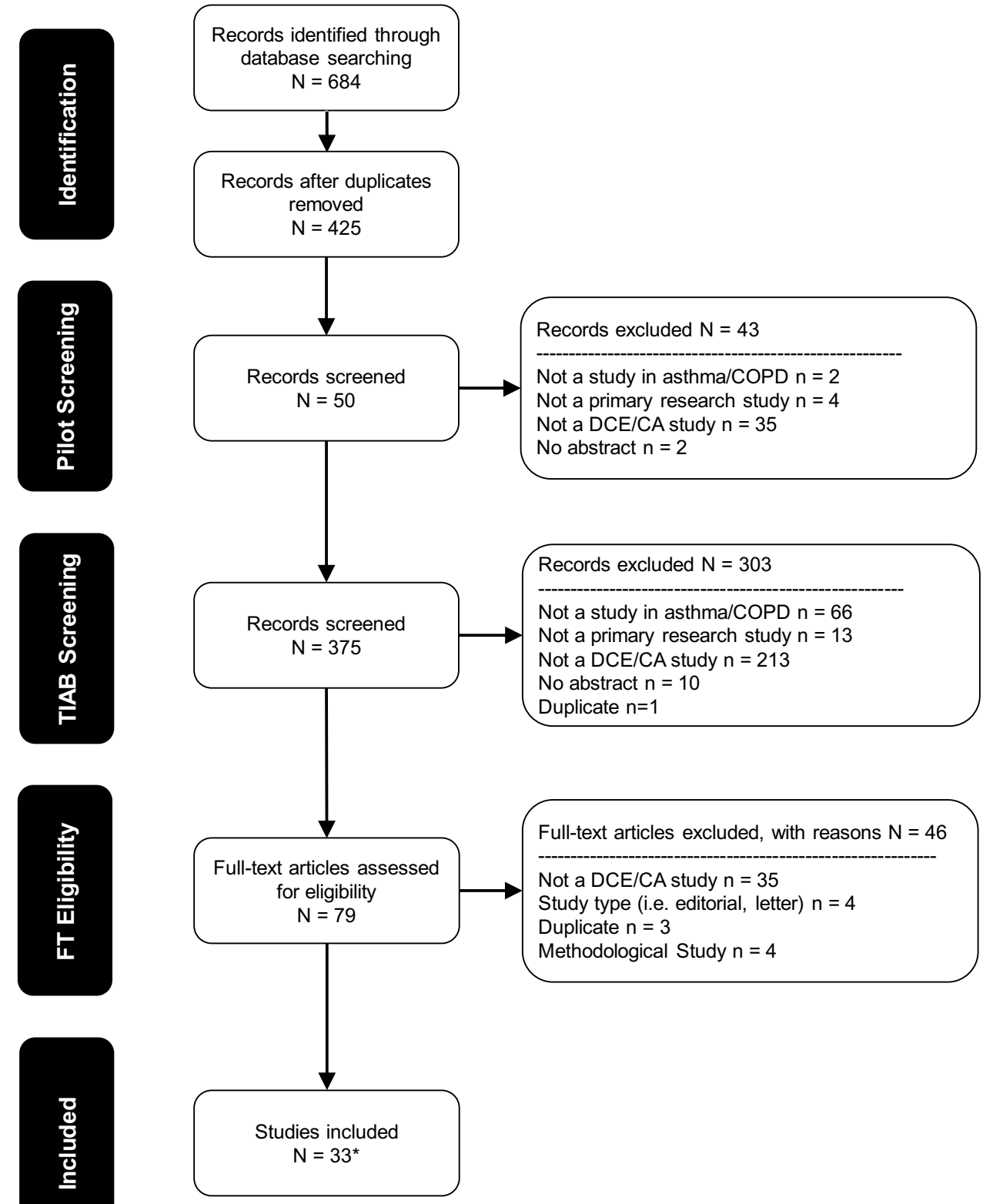

facilities available in the location of administration (e.g. the availability of a private area) or the consistency with which patients are able to see the same clinician for treatment. Most studies ( $n=20,71 \%$ ) were conducted in a patient-only sample, and a majority were conducted in the US $(n=8$, $29 \%)$ or UK $(n=8,29 \%)$.

Study design and analysis characteristics are listed in Table 2. Studies included a mean of 6.7 attributes (standard deviation [SD] 2.4), with a minimum of 2 and maximum of 15 . Many studies $(n=19,68 \%)$ reported the use of a qualitative phase in developing their attributes and levels, frequently taking the form of patient interviews ( $n=9,47 \%)$, patient focus groups $(n=8,42 \%)$ and clinician interviews $(n=6,32 \%)$.
The models most frequently used in analysis were the multinomial and mixed/random parameter logit models (each $n=9,32 \%$ ). Studies most frequently reported results using coefficients $(n=22,79 \%)$. Analysis of the existence or extent of preference heterogeneity varied between studies. The majority ( $n=21,75 \%$ ) accounted for variation in preferences between specific subgroups of the study sample (e.g. explained preference heterogeneity), with just over half of those $(52 \%)$ validating their findings through formal statistical assessment, for example through testing for differences in preferences between subgroups or through interaction modelling. The factors most commonly used to determine explained preference heterogeneity were sociodemographic ( $n=16,76 \%)$ and clinical $(n=13,62 \%)$ characteristics. 
Table 1 Study characteristics of 28 DCEs published in asthma and COPD between 1997 and 2020

\begin{tabular}{|c|c|c|c|}
\hline Characteristic & Pooled sample $(n=28)$ & Asthma sample $^{\mathrm{a}}(n=19)$ & COPD sample ${ }^{\mathrm{b}}(n=12)$ \\
\hline \multicolumn{4}{|l|}{ Sample size } \\
\hline Mean (SD) & $337.7(413.7)$ & $284.7(331.3)$ & $337.2(300.7)$ \\
\hline Min-max & $(42-1957)$ & $(42-1401)$ & $(49-1147)$ \\
\hline$\leq 150$ & $9(32)$ & $8(42)$ & $3(25)$ \\
\hline $151-200$ & $5(18)$ & $4(21)$ & $2(17)$ \\
\hline $201-250$ & $2(7)$ & $1(5)$ & $2(17)$ \\
\hline $251-300$ & $4(14)$ & $2(11)$ & $1(8)$ \\
\hline $300+$ & $8(29)$ & $4(21)$ & $4(33)$ \\
\hline \multicolumn{4}{|l|}{ Study subject } \\
\hline Inhaler treatment & $16(57)$ & $11(58)$ & $8(67)$ \\
\hline Non-specific treatment & $4(14)$ & $3(16)$ & $1(8)$ \\
\hline Symptom and QoL & $3(11)$ & $2(11)$ & $1(8)$ \\
\hline Service delivery & $2(7)$ & $1(5)$ & $1(8)$ \\
\hline Treatment and service delivery & $3(11)$ & $2(11)$ & $1(8)$ \\
\hline \multicolumn{4}{|l|}{ Year of publication, $n(\%)$} \\
\hline $1997-2000$ & $1(4)$ & $1(5)$ & $0(0)$ \\
\hline 2001-2005 & $3(11)$ & $3(16)$ & $0(0)$ \\
\hline 2006-2010 & $9(32)$ & $9(47)$ & $0(0)$ \\
\hline 2011-2015 & $6(21)$ & $1(5)$ & $5(42)$ \\
\hline $2016-2020$ & $9(32)$ & $5(26)$ & $7(58)$ \\
\hline \multicolumn{4}{|l|}{ Responder type, $n(\%)$} \\
\hline Patient & $20(71)$ & $15(79)$ & $8(67)$ \\
\hline Clinician & $1(4)$ & $0(0)$ & $1(8)$ \\
\hline Caregiver & $2(7)$ & $2(11)$ & $0(0)$ \\
\hline General population & $1(4)$ & $1(5)$ & $0(0)$ \\
\hline Patient + clinician & $1(4)$ & $0(0)$ & $1(8)$ \\
\hline Patient + caregiver & $2(7)$ & $1(5)$ & $1(8)$ \\
\hline Patient + general population & $1(4)$ & $0(0)$ & $1(8)$ \\
\hline \multicolumn{4}{|l|}{ Country, $n(\%)$} \\
\hline Australia & $4(14)$ & $4(21)$ & $0(0)$ \\
\hline Canada & $1(4)$ & $1(5)$ & $0(0)$ \\
\hline Denmark & $1(4)$ & $0(0)$ & $1(8)$ \\
\hline France & $3(11)$ & $1(5)$ & $3(25)$ \\
\hline Germany & $3(11)$ & $0(0)$ & $3(25)$ \\
\hline Netherlands & $3(11)$ & $2(11)$ & $2(17)$ \\
\hline New Zealand & $1(4)$ & $0(0)$ & $0(0)$ \\
\hline Spain & $1(4)$ & $1(5)$ & $0(0)$ \\
\hline Sweden & $1(4)$ & $1(5)$ & $0(0)$ \\
\hline Turkey & $1(4)$ & $0(0)$ & $1(8)$ \\
\hline UK & $8(29)$ & $6(32)$ & $3(25)$ \\
\hline US & $8(29)$ & $5(26)$ & $4(33)$ \\
\hline
\end{tabular}

$C O P D$ chronic obstructive pulmonary disease, $D C E s$ discrete choice experiments, $Q o L$ quality of life, $S D$ standard deviation, $U K$ United Kingdom, US United States

${ }^{a}$ Asthma sample includes studies conducted in asthma or asthma + COPD samples

${ }^{\mathrm{b}}$ COPD sample includes studies conducted in COPD or asthma + COPD samples

Unexplained preference heterogeneity was assessed in 11 studies (39\%), most frequently through mixed logit models $(n=7,64 \%)$. Ten studies $(n=36 \%)$ accounted for both explained and unexplained preference heterogeneity. 
Table 2 Study design and analysis characteristics of 28 DCEs published in asthma and COPD between 1997 and 2020

\begin{tabular}{|c|c|c|c|}
\hline Characteristic & $\begin{array}{l}\text { Pooled sam- } \\
\text { ple }(n=28)\end{array}$ & $\begin{array}{l}\text { Asthma } \\
\text { sample }^{\mathrm{a}} \\
(n=19)\end{array}$ & $\begin{array}{l}\text { COPD } \\
\text { sample }^{b} \\
(n=12)\end{array}$ \\
\hline Qualitative phase, $n(\%)$ & $19(68)$ & $13(68)$ & $9(75)$ \\
\hline Focus group & $10(53)$ & $6(46)$ & $6(67)$ \\
\hline Interview & $11(58)$ & $8(62)$ & $5(56)$ \\
\hline \multicolumn{4}{|l|}{ Number of attributes } \\
\hline Mean (SD) & $6.7(2.4)$ & $6.1(2.0)$ & $7.8(2.5)$ \\
\hline Min-max & $(2-15)$ & $(2-10)$ & $(6-15)$ \\
\hline $2-5$ & $6(21)$ & $6(32)$ & $0(0)$ \\
\hline $6-10$ & $21(75)$ & $13(68)$ & $11(92)$ \\
\hline $11-15$ & $1(4)$ & $0(0)$ & $1(8)$ \\
\hline \multicolumn{4}{|l|}{ Analysis models, $n(\%)$} \\
\hline Mixed/random parameters logit & $9(32)$ & $5(26)$ & $5(42)$ \\
\hline Multinomial logit & $9(32)$ & $6(32)$ & $5(42)$ \\
\hline Latent class logit & $2(7)$ & $1(5)$ & $1(8)$ \\
\hline Hierarchical Bayes & $1(4)$ & $0(0)$ & $1(8)$ \\
\hline Linmap function & $1(4)$ & $1(5)$ & $0(0)$ \\
\hline Logistic regression & $1(4)$ & $1(5)$ & $0(0)$ \\
\hline Random effects probit & $4(14)$ & $4(21)$ & $0(0)$ \\
\hline Rank ordered logit & $1(4)$ & $1(5)$ & $1(8)$ \\
\hline Nested logit model & $1(4)$ & $1(5)$ & $0(0)$ \\
\hline Separate binary logit & $1(4)$ & $1(5)$ & $0(0)$ \\
\hline Not reported & $3(11)$ & $2(11)$ & $1(8)$ \\
\hline \multicolumn{4}{|l|}{ Presentation of findings ${ }^{\mathrm{c}}, n(\%)$} \\
\hline Coefficients & $22(79)$ & $16(84)$ & $8(67)$ \\
\hline Marginal rates of substitution & $12(43)$ & $8(42)$ & $5(42)$ \\
\hline Willingness to pay & $11(92)$ & $8(100)$ & $4(80)$ \\
\hline Relative attribute importance & $10(36)$ & $7(37)$ & $4(33)$ \\
\hline Odds ratios & $4(14)$ & $3(16)$ & $3(25)$ \\
\hline Direct treatment comparison & $1(4)$ & $0(0)$ & $1(8)$ \\
\hline Predicted choice probability & $6(21)$ & $4(21)$ & $2(17)$ \\
\hline Self-predicted adherence (\%) & $1(4)$ & $1(5)$ & $0(0)$ \\
\hline Analysis of explained preference heterogeneity, $n(\%)$ & $21(75)$ & $14(74)$ & $10(83)$ \\
\hline With statistical testing of difference or interaction model & $11(52)$ & $10(71)$ & $3(30)$ \\
\hline With no statistical testing of difference & $10(48)$ & $4(29)$ & $7(70)$ \\
\hline \multicolumn{4}{|l|}{$\begin{array}{l}\text { Characteristics used in the assessment of explained prefer- } \\
\text { ence heterogeneity, } n(\%)\end{array}$} \\
\hline Sociodemographic characteristics & $16(76)$ & $10(71)$ & $9(90)$ \\
\hline Age & $7(33)$ & $4(29)$ & $6(60)$ \\
\hline Sex & $8(38)$ & $6(43)$ & $5(50)$ \\
\hline Race & $1(4)$ & $1(7)$ & $0(0)$ \\
\hline Education level & $4(19)$ & $4(29)$ & $1(10)$ \\
\hline Income level & $3(14)$ & $3(21)$ & $1(10)$ \\
\hline Country & $3(14)$ & $1(7)$ & $2(20)$ \\
\hline Responder type (e.g. patient vs clinician) & $4(19)$ & $1(7)$ & $3(30)$ \\
\hline Other & $2(10)$ & $2(14)$ & $0(0)$ \\
\hline Clinical characteristics & $13(62)$ & $9(64)$ & $7(70)$ \\
\hline Duration of disease & $2(10)$ & $2(14)$ & $1(10)$ \\
\hline Severity of disease & $7(33)$ & $3(21)$ & $6(60)$ \\
\hline Disease (e.g. asthma vs COPD) & $3(14)$ & $3(21)$ & $3(30)$ \\
\hline Treatment preference pre-DCE & $2(10)$ & $2(14)$ & $0(0)$ \\
\hline
\end{tabular}


Table 2 (continued)

\begin{tabular}{lccc}
\hline Characteristic & $\begin{array}{c}\text { Pooled sam- } \\
\text { ple }(n=28)\end{array}$ & $\begin{array}{c}\text { Asthma } \\
\text { sample }^{\mathrm{a}} \\
(n=19)\end{array}$ & $\begin{array}{c}\text { COPD } \\
\text { sample }^{\mathrm{b}} \\
(n=12)\end{array}$ \\
\hline Disease-related QoL & $2(10)$ & $2(14)$ & $0(0)$ \\
Analysis of unexplained preference heterogeneity & $11(39)$ & $6(32)$ & $6(50)$ \\
Mixed Logit & $7(64)$ & $4(67)$ & $4(67)$ \\
Latent Class Logit & $2(10)$ & $1(17)$ & $1(17)$ \\
Hierarchical Bayes Multinomial Logit & $1(9)$ & $0(0)$ & $1(17)$ \\
Individual level RI & $1(9)$ & $1(17)$ & $0(0)$ \\
Reporting criteria & & & \\
Criteria 1-attribute development, $n(\%)$ & $22(79)$ & $15(79)$ & $9(75)$ \\
Criteria 2-pre-testing, $n$ (\%) & $18(64)$ & $13(68)$ & $7(58)$ \\
Criteria 3-experimental design, $n(\%)$ & $24(86)$ & $16(84)$ & $10(83)$ \\
Criteria 4-behavioural outcomes + uncertainty, $n(\%)$ & $10(36)$ & $7(37)$ & $5(42)$ \\
Studies reporting on 0 criterion, $n(\%)$ & $2(7)$ & $1(5)$ & $2(17)$ \\
Studies reporting on 1 criterion, $n(\%)$ & $3(11)$ & $2(11)$ & $1(8)$ \\
Studies reporting on 2 criteria, $n(\%)$ & $5(18)$ & $4(21)$ & $1(8)$ \\
Studies reporting on 3 criteria, $n(\%)$ & $11(39)$ & $7(37)$ & $4(33)$ \\
Studies reporting on 4 criteria, $n(\%)$ & $7(25)$ & $5(26)$ & $4(33)$ \\
\hline
\end{tabular}

$C O P D$ chronic obstructive pulmonary disease, $D C E s$ discrete choice experiments, $Q o L$ quality of life, $S D$ standard deviation

${ }^{a}$ Asthma sample includes studies conducted in asthma or asthma + COPD samples

${ }^{\mathrm{b}}$ COPD sample includes studies conducted in COPD or asthma + COPD samples

${ }^{\mathrm{c}}$ Not mutually exclusive

Reporting practices were reviewed for all studies, as described in the methods section. Overall, of the chosen criteria, experimental design features were those most frequently reported across studies $(n=24,86 \%)$. Seventy-nine percent of studies $(n=22)$ reported the attribute development process, while $64 \%(n=18)$ reported on qualitative testing of the DCE instrument. Ten studies (36\%) reported results as a behavioural outcome inclusive of a measure of uncertainty. Seven studies (25\%) reported across all four criteria.

\subsection{Attribute Categories}

The breakdown of attributes across studies is presented in Table 3. Attributes were broken down across five broad categories: symptoms and treatment benefits, treatment risks, treatment convenience, treatment cost, and other. Each category was further broken down based on specific attribute definitions. Within the broad attribute categories, there were no major differences between the number of asthma and COPD studies including each concept, with the exception of treatment convenience, which was included in $68 \%$ of asthma studies and in $82 \%$ of COPD studies.

The attribute type most commonly included in studies was symptoms and treatment benefits, with 23 studies (82\%) including at least one attribute within this category. Specific attribute definitions included symptoms $(n=18,64 \%)$, exacerbations $(n=8,29 \%)$, onset $(n=5,18 \%)$, and other benefit $(n=4,14 \%)$.

Similarly, treatment convenience was commonly included as an attribute within DCEs, with 19 studies (68\%) including at least one convenience attribute. Definitions within this category included frequency of use and inhaler features (both $n=11,39 \%)$, treatment type $(n=7,25 \%)$ including inhaler type (e.g. dry powder inhaler, metered-dose inhaler), and number of inhalers $(n=5,18 \%)$. No studies included in this review assessed preferences for nebulised treatments.

Treatment cost was included as an attribute in 17 studies (61\%) and covered out-of-pocket treatment costs for patients $[24,27,29,31-38,41,42,49,50]$, cost to the government [34] and travel costs associated with receiving the medication [48].

Thirteen studies (46\%) included at least one risk attribute. Risk attributes covered the frequency of adverse events, severity of adverse events, adverse event type, and steroid dosing. Higher steroid doses are associated with worse and more prolonged adverse events [59-62] and were therefore deemed to be a risk concept for the purposes of this categorisation. Although just under half of studies included a treatment risk attribute, the number of treatment risk attributes assessed relative to the number of symptom or treatment benefit attributes is small. Only 19 risk attributes were included across 13 studies, compared with 70 symptom or treatment benefit attributes included across 23 studies. 
Table 3 Number of studies including attributes within different categories

\begin{tabular}{|c|c|c|c|}
\hline Characteristic & $\begin{array}{l}\text { Pooled sample } \\
(n=28)\end{array}$ & $\begin{array}{l}\text { Asthma sample }{ }^{\mathrm{a}} \\
(n=19)\end{array}$ & $\begin{array}{l}\text { COPD sample }{ }^{\mathrm{b}} \\
(n=12)\end{array}$ \\
\hline $\begin{array}{l}\text { Symptoms and treatment benefits } \\
{[15,22,24,26-28,31-38,40-43,45,47-50]}\end{array}$ & $23(82)$ & $17(89)$ & $8(67)$ \\
\hline $\begin{array}{l}\text { Exacerbations } \\
\text { Frequency of exacerbation }(n=7) \text {, Need for rescue medicine }(n=2) \\
{[15,22,26,32,36,38,49,50]}\end{array}$ & $8(29)$ & $5(26)$ & $5(42)$ \\
\hline $\begin{array}{l}\text { Symptoms } \\
\text { Symptom relief }(n=7) \text {, Symptom frequency }(n=3) \text {, Symptom severity }(n=1) \text {, Symptom type }(n=14) \text {, } \\
\quad \text { Symptom impact }(n=20) \\
{[22,24,26,28,31-35,37,38,40,41,43,47-50]}\end{array}$ & $18(64)$ & 14 (74) & $5(42)$ \\
\hline $\begin{array}{l}\text { Onset } \\
\text { Speed }(n=7), \text { Feeling }(n=2) \\
{[15,27,31,32,47]}\end{array}$ & $5(18)$ & $3(16)$ & $3(25)$ \\
\hline $\begin{array}{l}\text { Other } \\
\text { Chance of needing to change treatment }(n=1) \text {, Probability of efficacy }(n=1) \text {, Efficient delivery to lung } \\
\quad(n=1) \text {, Duration of action }(n=1) \\
{[31,34,42,45]}\end{array}$ & $4(14)$ & $3(16)$ & $1(8)$ \\
\hline $\begin{array}{l}\text { Treatment risk } \\
{[15,22,24,28,32,33,35,36,38,41,45,48,53]}\end{array}$ & $13(46)$ & $9(47)$ & $5(42)$ \\
\hline $\begin{array}{l}\text { Frequency of AE } \\
\text { Likelihood }(n=4) \text {, Categorical }(n=1) \\
{[24,36,38,45,48]}\end{array}$ & $5(18)$ & $3(16)$ & $2(17)$ \\
\hline $\begin{array}{l}\text { Severity of AE } \\
\text { [32] }\end{array}$ & $1(4)$ & $0(0)$ & $1(8)$ \\
\hline $\begin{array}{l}\text { AE type } \\
\text { Oral thrush, hoarseness, tremors, osteoporosis, pneumonia, hospitalisation }(n=8) \\
{[15,33,35,41,53]}\end{array}$ & $5(18)$ & $4(21)$ & $2(17)$ \\
\hline $\begin{array}{l}\text { Steroid dose } \\
\text { Strength of ICS dose }(n=2) \\
{[22,28]}\end{array}$ & $2(7)$ & $2(11)$ & $0(0)$ \\
\hline $\begin{array}{l}\text { Treatment convenience } \\
{[15,22,23,25,28-36,38,41-43,47,49]}\end{array}$ & $19(68)$ & $13(68)$ & $9(75)$ \\
\hline $\begin{array}{l}\text { Frequency of use } \\
\text { Frequency of use }(n=8) \text {, Frequency of visits }(n=1) \text {, Dosing flexibility }(n=1) \\
{[15,23,30,33,35,36,41-43,47,49]}\end{array}$ & $11(39)$ & 7 (37) & $6(50)$ \\
\hline $\begin{array}{l}\text { Type of treatment } \\
\text { Route of administration including inhaler type (e.g. dry powder inhaler, metered-dose inhaler })(n=6) \text {, } \\
\text { Strength of medicine }(n=1) \\
{[15,22,31,33-35,42]}\end{array}$ & $7(25)$ & $6(32)$ & $2(17)$ \\
\hline $\begin{array}{l}\text { Number of inhalers } \\
\text { Number of inhalers }(n=4) \text {, Need for additional acute-symptom inhaler }(n=1) \\
{[28,31,36,38,41]}\end{array}$ & $5(18)$ & $4(21)$ & $1(8)$ \\
\hline $\begin{array}{l}\text { Inhaler features } \\
\text { Cleaning }(n=2) \text {, Shape/convenience }(n=7) \text {, Monitoring peak flow }(n=2) \text {, Dosing }(n=25)(\text { e.g. dose } \\
\text { release, preparation, etc.), Indicates empty }(n=1) \text {, Reusability }(n=2) \text {, Technology }(n=1) \\
{[15,23,25,29,30,32,33,35,36,42,49]}\end{array}$ & $11(39)$ & $6(32)$ & $8(67)$ \\
\hline $\begin{array}{l}\text { Treatment cost } \\
{[24,27,29,31-38,41,42,48-50,53]}\end{array}$ & $17(61)$ & $12(63)$ & $7(58)$ \\
\hline $\begin{array}{l}\text { Other } \\
{[24,28,30,33,35,42,43,48,50,53]}\end{array}$ & $10(36)$ & $8(42)$ & $4(33)$ \\
\hline $\begin{array}{l}\text { Other: Treatment } \\
\text { Class of compound }(n=1) \text {, Patient satisfaction }(n=1) \\
{[42]}\end{array}$ & $1(4)$ & $0(0)$ & $1(8)$ \\
\hline $\begin{array}{l}\text { Other: Evidence } \\
\text { Evidence of compliance }(n=1) \text {, Duration of evidence }(n=1), \text { FDA approval }(n=1) \\
{[30,42,50]}\end{array}$ & $3(11)$ & $2(11)$ & $1(8)$ \\
\hline $\begin{array}{l}\text { Other: Service } \\
\text { HCP interaction or information }(n=10) \text {, Advice }(n=5) \text {, Other }(n=4) \\
{[24,28,33,35,42,43,48,53]}\end{array}$ & $8(29)$ & $6(32)$ & $4(33)$ \\
\hline
\end{tabular}

$\overline{A E \text { adverse event, } C O P D \text { chronic obstructive pulmonary disease, FDA Food and Drug Administration, } H C P \text { health care provider, } I C S \text { inhaled }}$ corticosteroids

${ }^{\mathrm{a}}$ Asthma sample includes studies conducted in asthma or asthma + COPD samples

${ }^{\mathrm{b}}$ COPD sample includes studies conducted in COPD or asthma + COPD samples 
The remaining attributes were categorised as 'other'. Ten studies (36\%) included an attribute in the 'other' category. Concepts related to treatments, evidence, or service delivery.

\subsection{Treatment Preferences}

Table 4 provides a breakdown of the attribute importance rankings across all studies. Across the 28 studies included, 44 models were estimated due to the reporting of multiple sets of preference estimates within some studies. Multiple models were estimated within one study based on subgroups such as disease (e.g. asthma and COPD) or responder type (e.g. patient and clinician). Across the estimated models for which ranking data was available and relative to the number of studies including such attributes, symptom and treatment benefits were those most frequently $(n=26,72 \%)$ ranked as the most important. Risk was the second most frequently ranked as the most important attribute $(n=7,39 \%)$, followed by convenience attributes in $22 \%(n=6)$ of models. Cost attributes were those least frequently ranked as the most important, in only $8 \%(n=2)$ of the models in which they were included.

Differences were identified in attribute rankings across both disease and study subjects (ESM, Table S2 to Table S6). Where included, symptom and treatment benefit attributes were ranked as the most important attribute more frequently in asthma studies $(n=20,80 \%)$ than COPD studies $(n=7$, $54 \%)$. The reverse was true of risk attributes, which were ranked as the most important in only $18 \%(n=2)$ of asthma studies, but $63 \%(n=5)$ of COPD studies. Across study subjects, symptom and treatment benefits were often those ranked as most important, with the exception of service delivery-based studies, in which the only benefit attribute included was not ranked as the most important. Notably, despite inhaler treatment studies assessing preferences

Table 4 Attribute category ranking of DCEs published in asthma and COPD between 1997 and 2020

\begin{tabular}{llll}
\hline Category & $\begin{array}{l}\text { Pooled sample } \\
N(\%)\end{array}$ & $\begin{array}{l}\text { Asthma sample }^{\mathrm{a}} \\
N(\%)\end{array}$ & $\begin{array}{l}\text { COPD sample } \\
N(\%)\end{array}$ \\
\hline $\begin{array}{l}\text { Symptom or } \\
\text { treatment } \\
\text { benefit }\end{array}$ & $26(72)$ & $20(80)$ & $7(54)$ \\
Convenience & $6(22)$ & $3(19)$ & $4(29)$ \\
Risk & $7(39)$ & $2(18)$ & $5(63)$ \\
Cost & $2(8)$ & $1(6)$ & $2(22)$ \\
Other & $3(20)$ & $2(18)$ & $1(25)$ \\
\hline
\end{tabular}

$C O P D$ chronic obstructive pulmonary disease, $D C E s$ discrete choice experiments

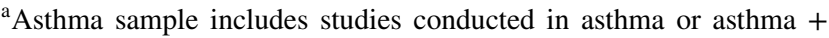
COPD samples

${ }^{\mathrm{b}}$ COPD sample includes studies conducted in COPD or asthma + COPD samples across a range of convenience-based attributes, such attributes were only ranked as most important in $25 \%(n=5)$ of studies in which they were included.

\section{Discussion}

The aim of this paper was to provide an up-to-date and critical review of published DCEs in asthma or COPD, including an assessment of the consistency in reporting across key criteria. A total of 28 DCEs were included in the final analysis, split between asthma $(n=16,57 \%), \operatorname{COPD}(n=9,32 \%)$ and mixed asthma/COPD $(n=3,11 \%)$ samples.

The number of asthma and COPD DCEs published rose over the review period, with the first study published in 1997. There was a rise in the number of publications in the period 2006-2010 $(n=9,32 \%)$, followed by a reduced number in the following period (2011-2015; $n=6,21 \%)$. It is unclear what motivated the increase in publications in the 5 years from 2006, although it is noteworthy that all publications in this period were conducted in an asthma sample; this may be a reflection of changes to the treatment pathway for severe or uncontrolled asthma, with the first biologic in asthma approved by the FDA in 2003 [63]. Nine studies (32\%) were published in the 5 years (2016-2020) prior to this review.

A majority of the studies $(n=16,57 \%)$ assessed stakeholders' preferences for features of inhaler treatments, with a small number focusing on non-specific treatments (e.g. inhaled or oral) $(n=4,14 \%)$, symptoms or QoL $(n=3$, $11 \%)$ or service delivery $(n=2,7 \%)$. Notably, no study assessed preferences for biologic treatments in asthma or COPD, despite a number of approvals $[64,65]$ for such therapies in recent years and increasing use of such therapies in moderate-to-severe disease. Unlike standard therapies, biologics are administered via injection, and an understanding of preferences for the varying modes of administration across treatment types is needed. Further, biologic therapies are associated with a unique and sometimes severe risk profile including, in some therapies, the risk of anaphylaxis [64], and insight on stakeholders' tolerance for such risks will support shared decision making between patient and clinician.

Eight (29\%) studies were conducted in both the US and the UK, with several others conducted in Australia $(n=4$, $14 \%)$, France $(n=3,11 \%)[25,29,42]$, Germany $(n=3$, $11 \%)[36,42,47]$ and the Netherlands $(n=3,11 \%)[26,38$, 53]. No studies were conducted in South America, Africa or Asia, meaning that no evidence is currently available on stakeholders' preferences across those regions. To better understand preferences for asthma and COPD treatments, services and symptoms, future research should seek to assess 
preferences in those regions currently under- or not represented in the literature.

Through our analysis, we identified the following five key attribute categories used in asthma/COPD DCEs: symptoms and treatment benefits, treatment risks, treatment convenience, treatment cost, and other. The frequency with which attribute categories were included in asthma/COPD DCEs largely aligns with previous reviews of health-based DCEs, with treatment benefit and cost both frequently included, and risk less commonly so $[14,66]$. Symptom and treatment benefit attributes, included in 23 studies ( $82 \%$ ), were those most frequently ranked as most important $(n=26,72 \%)$.

Treatment adherence is one of the key issues in managing asthma and COPD [67, 68], with both the GINA and GOLD reports citing issues with adherence as a contributory factor in uncontrolled disease $[3,4]$, resulting in more frequent exacerbations, and higher rates of hospitalisation and death. Patient-reported reasons for poor adherence include, among others, concerns around drug safety [69, 70]. Despite this, less than half ( $n=13,46 \%$ ) of the DCEs reviewed included a risk attribute, limiting the extent to which we are able to understand patients' tolerance for treatment-emergent risks. Developing an understanding of treatment-risk tolerance in asthma and COPD patients, including the acceptable magnitude of risk and risk type, can be used to inform the development of future treatments. Further, through the assessment of preference heterogeneity, it may be possible to determine subgroups of patients more tolerant of specific treatments and risks, allowing HCPs to tailor prescribing habits. Notably, risk was ranked as the most important attribute in $39 \%$ of the models in which it was included, suggesting that, despite limited assessment through DCE studies of patients' tolerance for treatment risks, it is an outcome of importance to patients and thus warrants further research. Without an assessment of the benefit-risk trade-offs participants are willing to make, the use of the resulting preference data in decision making is limited in scope. The risk types where risk attributes were ranked as most important were varied, including frequency of adverse events, likelihood of adverse events, severity of side effects and specific adverse event types.

Convenience was the second most common attribute type, included in $68 \%(n=19)$ of studies, ahead of both cost and risk. Both the GINA and GOLD reports and the recent 2020 Focused Updates to the Asthma Management Guidelines cite the importance of patients' ability to use the treatment device appropriately [3, 4, 13], endorsing regular assessment of inhaler technique. A recent cross-sectional study found that almost half of the patients were using their inhaler improperly, which was associated with poorer asthma control [71]. Understanding patients' preferences for inhaler features can be used to inform the design of future devices to better suit the needs, wants or abilities of patients, which may lead to an improvement in clinical outcomes in the long term [72]. In our assessment of preferences, convenience attributes were ranked as the most important attribute in $22 \%$ $(n=6)$ of models where included.

Although cost was included in more than half of the studies identified ( $n=17,61 \%$ ), in our assessment of preferences it tended to rank below other attribute concepts, with cost being the most important attribute in only two models (9\%). Although cost can be a relevant attribute to include in some cases, the variability of cost based on pharmaceutical rebate and insurance status from the patients' perspective means that in some instances, patients may not attend to this attribute, or preferences may be very heterogenous. Many of the studies that included cost $(n=11,65 \%)$ used this attribute to determine participants' willingness to pay for improvements in other attributes.

Differences were found in attribute rankings based on both disease type and study subject, providing insight on the differing priorities between these groups. Asthma stakeholders tended to rank treatment benefit as more important than risk, while COPD stakeholders ranked risk as important more frequently than benefit. It is unclear what may motivate such preference patterns, and future research could usefully determine contributing factors, including patients' risk perceptions between the disease types. In terms of study subject, although inhaler treatments were the most common study subject, attributes specific to this treatment type (i.e. inhaler and convenience-related features) were ranked as most important in only $25 \%$ of the studies in which they were included. Symptom and treatment benefit attributes were most frequently ranked as most important across study types with the exception of studies on service delivery, in which risk, cost and other (i.e. attributes relating to other treatment factors, treatment evidence or the service delivery) were ranked as most important, warranting more research into preferences on how services and treatments are delivered to the patient.

Studies included in our review were assessed based on their reporting of four key criteria. Studies most consistently reported across attribute development and experimental design criteria, with around one third $(n=10,36 \%)$ extending their analysis to report on behavioural outcomes, such as attribute trade-offs (i.e. marginal rates of substitution), relative attribute importance, or predicted choice probabilities, with the inclusion of measures of uncertainty. This aligns with a recent review that found that many DCEs fail to report on the certainty of MRS estimates, limiting the reliability of results for readers [15]. The limited extent to which studies reported on attribute trade-offs highlights a gap in the current research, with many not making use of the rich data and insight on attribute trade-offs that such a methodology offers. Results of the criteria assessment also indicated that many DCEs are fielded without pre-testing 
of the elicitation instrument. The International Society for Pharmacoeconomics and Outcomes Research's (ISPOR) taskforce on good research practices for conjoint analysis recommends the use of a pilot phase to test and refine the instrument prior to data collection [20,73], ensuring that participants attend to all attributes, that no significant other methodological issues arise, and that participants understand the wording and concepts included in the survey. Although no formal assessment of study quality was undertaken in this review, quality assessment frameworks have been developed by other authors previously, including the PREFS checklist [21], and guidance published by the FDA highlighting the importance of adhering to quality measures to ensure robust study designs, illustrating the various ways in which study quality can be implemented and assessed [10-12]. These existing frameworks, specifically the PREFS checklist, focus on study purpose, sampling, explanations of the elicitation method, reporting of findings for the total sample and the implementation of significance testing, whilst the four criteria assessed in this review focus on attribute development, instrument testing, the reporting of experimental design characteristics and the use of behavioural outcomes with measures of uncertainty to report study results.

As expected, explained preference heterogeneity was accounted for more frequently in the included DCEs than unexplained, which was assessed in 39\% $(n=11)$ of studies. Of those studies assessing explained heterogeneity $(n=21$, $75 \%)$, just over half ( $n=11,52 \%)$ validated their findings through formal statistical assessment, for example through testing for differences in preferences between subgroups or through interaction modelling. Sociodemographic characteristics $(n=16,76 \%)$ were more frequently used in the assessment of explained preference heterogeneity than clinical characteristics $(n=13,62 \%)$. Within those categories, those most commonly assessed were sex $(n=8,38 \%)$, age $(n=7,33 \%)$, and disease severity $(n=7,33 \%)$ measured by disease-specific outcome measures such as asthma control test (ACT) or COPD assessment test (CAT) scores.

No grey literature search was conducted as part of this review. Further, only a sample $(n=3+10 \%$ for quality control) of the included studies were double extracted, with the remaining studies split between two analysts for single extraction. The impact of this is expected to be limited, with no major differences in extraction style identified after completion of the third pilot extraction.

\section{Conclusion}

Our review found a significant number of studies published on patients' or other relevant stakeholders' preferences for treatments of asthma and COPD. Most studies assessed preferences for inhaled treatments, with few studies assessing preferences for other treatment types, QoL or service delivery. Studies tended to focus on treatment benefit and convenience, with less evidence generated on participants' risk tolerance, despite risk emerging as an attribute ranked highly in terms of importance, where included. Without further assessment of the benefit-risk trade-offs participants are willing to make, the use of preference data in decision making is limited in scope. An assessment of study reporting across key criteria found that, despite recommendations, the number of DCEs undergoing qualitative pre-testing prior to data collection was limited, and the majority did not assess behavioural outcomes with a corresponding measure of uncertainty. Implementation of formal quality criteria in conducting preference research will maximise the robustness of such studies, providing reliable insights that can be used to promote shared decision making between patient and clinician.

Supplementary Information The online version contains supplementary material available at https://doi.org/10.1007/s40271-021-00536-w.

\section{Declarations}

Funding This review was partially funded by AstraZeneca. AstraZeneca had no role in formulating the research question, data collection, analysis, or the decision to publish the results.

Conflicts of interest Hannah Collacott, Dian Zhang, Sebastian Heidenreich, and Tommi Tervonen are employees of Evidera, which provides consulting and other research services to pharmaceutical, medical device, and related organisations. In their salaried positions, they work with a variety of companies and organisations and are precluded from receiving payment or honoraria directly from these organisations for services rendered.

Availability of data and material All study data is available from the corresponding author (Tommi Tervonen) on request.

Guarantor statement Tommi Tervonen takes responsibility for the content of the manuscript, including the data and analysis.

Author contributions Hannah Collacott, Sebastian Heidenreich, and Tommi Tervonen participated in study conception, design, and planning. Hannah Collacott and Dian Zhang participated in screening and analysis. All authors contributed to interpretation of the data. Hannah Collacott wrote the initial manuscript draft, and all authors were involved in reviewing.

Acknowledgments The authors would like to thank Ruth Pereira and Ileen Gilbert (AstraZeneca) for critical review of the manuscript draft, and Fritz Hamme (Evidera) for his editorial review of the manuscript.

Open Access This article is licensed under a Creative Commons Attribution-NonCommercial 4.0 International License, which permits any non-commercial use, sharing, adaptation, distribution and reproduction in any medium or format, as long as you give appropriate credit to the original author(s) and the source, provide a link to the Creative Commons licence, and indicate if changes were made. The images or other third party material in this article are included in the article's Creative 
Commons licence, unless indicated otherwise in a credit line to the material. If material is not included in the article's Creative Commons licence and your intended use is not permitted by statutory regulation or exceeds the permitted use, you will need to obtain permission directly from the copyright holder. To view a copy of this licence, visit http://creativecommons.org/licenses/by-nc/4.0/.

\section{References}

1. van Haarst A, McGarvey L, Paglialunga S. Review of Drug development guidance to treat chronic obstructive pulmonary disease: US and EU perspectives. Clin Pharmacol Ther. 2019;106(6):1222-35. https://doi.org/10.1002/cpt.1540.

2. Upham JW, Chung LP. Optimising treatment for severe asthma. Med J Aust. 2018;209(S2):S22-7.

3. Global Initiative for Asthma. Global Strategy for Asthma Management and Prevention (2021 update). 2021. https://ginasthma.org/ wp-content/uploads/2021/05/GINA-Main-Report-2021-V2-WMS. pdf. Accessed 3 Jun 2021.

4. Global Initiative for Chronic Obstructive Lung Disease Inc. Pocket Guide to COPD: Diagnosis, Management, and Prevention. 2020. https://goldcopd.org/wp-content/uploads/2020/03/GOLD-2020POCKET-GUIDE-ver1.0_FINAL-WMV.pdf. Accessed 17 Dec 2020.

5. European Medicines Agency (EMA). EMA Regulatory Science to 2025: Strategic reflection. 2020. https://www.ema.europa.eu/en/ documents/regulatory-procedural-guideline/ema-regulatory-scien ce-2025-strategic-reflection_en.pdf. Accessed 20 May 2021.

6. Australian Government Department of Health. The Pharmaceutical Benefits Advisory Committee Guidelines. Appendix 6 Including nonhealth outcomes in a supplementary analysis. 2016. https://pbac.pbs.gov.au/appendixes/appendix-6-including-nonhe alth-outcomes-in-a-supplementary-analysis.html. Accessed 20 May 2021.

7. Institute for Quality and Efficiency in Health Care. General Methods. 2017. https://www.iqwig.de/methoden/general-methods_ version-5-0.pdf?rev=117386. Accessed 20 May 2021.

8. Marsh K, van Til JA, Molsen-David E, Juhnke C, Hawken N, Oehrlein EM, et al. Health preference research in europe: a review of its use in marketing authorization, reimbursement, and pricing decisions-report of the ISPOR stated preference research special interest group. Value Health. 2020;23(7):831-41. https://doi.org/ 10.1016/j.jval.2019.11.009.

9. Pharmaceutical Benefits Board. General guidelines for economic evaluations from the Pharmaceutical Benefits Board (LFNAR 2003:2). 2003. https://www.tlv.se/download/18.2e53241415e842c e95514e9/1510316396792/Guidelines-for-economic-evaluationsLFNAR-2003-2.pdf. Accessed 20 May 2021.

10. Johnson FR, Zhou M. Patient preferences in regulatory benefit-risk assessments: a US perspective. Value Health. 2016;19(6):741-5. https://doi.org/10.1016/j.jval.2016.04.008.

11. Food and Drug Administration. Patient preference informationvoluntary submission, review in premarket approval applications, humanitarian device exemption applications, and De Novo requests, and inclusion in decision summaries and device labeling. guidance for industry, food and drug administration staff, and other stakeholders. 2016. https://www.fda.gov/media/92593/ download. Accessed 22 Jan 2021.

12. Food and Drug Administration. Factors to Consider when making benefit-risk determinations in medical device premarket approval and De Novo classifications guidance for industry and food and drug administration staff. 2019. https://www.fda.gov/media/ 99769/download. Accessed 22 Jan 2021.
13. Expert Panel Working Group of the National Heart L, Blood Institute a, coordinated National Asthma E, Prevention Program Coordinating C, Cloutier MM, Baptist AP et al. 2020 focused updates to the asthma management guidelines: a report from the national asthma education and prevention program coordinating committee expert panel working group. J Allergy Clin Immunol. 2020;146(6):1217-70. https://doi.org/10.1016/j.jaci.2020.10.003.

14. Soekhai V, de Bekker-Grob EW, Ellis AR, Vass CM. Discrete choice experiments in health economics: past, present and future. Pharmacoeconomics. 2019;37(2):201-26. https://doi.org/10.1007/ s40273-018-0734-2.

15. Mott DJ, Chami N, Tervonen T. Reporting quality of marginal rates of substitution in discrete choice experiments that Elicit patient preferences. Value Health. 2020;23(8):979-84. https:// doi.org/10.1016/j.jval.2020.04.1831.

16. Bereza BG, Troelsgaard Nielsen A, Valgardsson S, Hemels ME, Einarson TR. Patient preferences in severe COPD and asthma: a comprehensive literature review. Int J Chron Obstruct Pulmon Dis. 2015;10:739-44. https://doi.org/10.2147/COPD.S82179.

17. de Bekker-Grob EW, Ryan M, Gerard K. Discrete choice experiments in health economics: a review of the literature. Health Econ. 2012;21(2):145-72. https://doi.org/10.1002/hec.1697.

18. Clark MD, Determann D, Petrou S, Moro D, de Bekker-Grob EW. Discrete choice experiments in health economics: a review of the literature. Pharmacoeconomics. 2014;32(9):883-902. https://doi. org/10.1007/s40273-014-0170-x.

19. Ryan M, Gerard K. Using discrete choice experiments to value health care programmes: current practice and future research reflections. Appl Health Econ Health Policy. 2003;2(1):55-64.

20. Bridges JF, Hauber AB, Marshall D, Lloyd A, Prosser LA, Regier DA, et al. Conjoint analysis applications in health - a checklist: a report of the ISPOR Good Research Practices for Conjoint Analysis Task Force. Value Health. 2011;14(4):403-13. https://doi.org/ 10.1016/j.jval.2010.11.013.

21. Joy SM, Little E, Maruthur NM, Purnell TS, Bridges JF. Patient preferences for the treatment of type 2 diabetes: a scoping review. Pharmacoeconomics. 2013;31(10):877-92. https://doi.org/10. 1007/s40273-013-0089-7.

22. Baggott C, Hansen P, Hancox RJ, Hardy JK, Sparks J, Holliday $\mathrm{M}$, et al. What matters most to patients when choosing treatment for mild-moderate asthma? Results from a discrete choice experiment. Thorax. 2020;75(10):842-8. https://doi.org/10.1136/thora xjnl-2019-214343.

23. Bogelund M, Hagelund L, Asmussen MB. COPD-treating nurses' preferences for inhaler attributes-a discrete choice experiment. Curr Med Res Opin. 2017;33(1):71-5. https://doi.org/10.1080/ 03007995.2016.1238353.

24. Bulcun E, Ekici M, Ekici A. Assessment of patients' preferences regarding the characteristics associated with the treatment of chronic obstructive pulmonary disease. Int J Chron Obstruct Pulmon Dis. 2014;9:363-8. https://doi.org/10.2147/COPD. S56229.

25. Chouaid C, Germain N, De Pouvourville G, Aballea S, Korchagina $\mathrm{D}$, Baldwin M, et al. Patient preference for chronic obstructive pulmonary disease (COPD) treatment inhalers: a discrete choice experiment in France. Curr Med Res Opin. 2019;35(5):785-92. https://doi.org/10.1080/03007995.2019.1574507.

26. Goossens LMA, Rutten-van Molken M, Boland MRS, Donkers B, Jonker MF, Slok AHM, et al. ABC Index: quantifying experienced burden of COPD in a discrete choice experiment and predicting costs. BMJ Open. 2017;7(12): e017831. https://doi.org/10.1136/ bmjopen-2017-017831.

27. Hauber AB, Mohamed AF, Johnson FR, Meddis D, Wagner S, O'Dowd L. Quantifying asthma patient preferences for onset of effect of combination inhaled corticosteroids and long-acting 
beta2-agonist maintenance medications. Allergy Asthma Proc. 2009;30(2):139-47. https://doi.org/10.2500/aap.2009.30.3205.

28. Haughney J, Fletcher M, Wolfe S, Ratcliffe J, Brice R, Partridge MR. Features of asthma management: quantifying the patient perspective. BMC Pulm Med. 2007;7:16. https://doi.org/10.1186/ 1471-2466-7-16.

29. Hawken N, Torvinen S, Neine ME, Amri I, Toumi M, Aballea $\mathrm{S}$, et al. Patient preferences for dry powder inhaler attributes in asthma and chronic obstructive pulmonary disease in France: a discrete choice experiment. BMC Pulm Med. 2017;17(1):99. https://doi.org/10.1186/s12890-017-0439-x.

30. Hitchcock W, Mellon M, Memran M, Parasuraman B, Ramachandran S, Walzer S. Caregiver preferences for pediatric asthma treatment delivery systems. Adv Ther. 2007;24(6):1240-53. https:// doi.org/10.1007/BF02877770.

31. Johansson G, Stallberg B, Tornling G, Andersson S, Karlsson GS, Falt K, et al. Asthma treatment preference study: a conjoint analysis of preferred drug treatments. Chest. 2004;125(3):916-23. https://doi.org/10.1378/chest.125.3.916.

32. Kawata AK, Kleinman L, Harding G, Ramachandran S. Evaluation of patient preference and willingness to pay for attributes of maintenance medication for chronic obstructive pulmonary disease (COPD). Patient. 2014;7(4):413-26. https://doi.org/10.1007/ s40271-014-0064-1.

33. King MT, Hall J, Lancsar E, Fiebig D, Hossain I, Louviere J, et al. Patient preferences for managing asthma: results from a discrete choice experiment. Health Econ. 2007;16(7):703-17. https://doi. org/10.1002/hec.1193.

34. Laba TL, Reddel HK, Zwar NJ, Marks GB, Roughead E, Flynn $\mathrm{A}$, et al. Does a patient-directed financial incentive affect patient choices about controller medicines for asthma? A discrete choice experiment and financial impact analysis. Pharmacoeconomics. 2019;37(2):227-38. https://doi.org/10.1007/s40273-018-0731-5.

35. Lancsar EJ, Hall JP, King M, Kenny P, Louviere JJ, Fiebig DG, et al. Using discrete choice experiments to investigate subject preferences for preventive asthma medication. Respirology. 2007;12(1):127-36. https://doi.org/10.1111/j.1440-1843.2006. 01005.x.

36. Lewis HB, Schroeder M, Gunsoy NB, Janssen EM, Llewellyn $\mathrm{S}$, Doll HA, et al. Evaluating patient preferences of maintenance therapy for the treatment of chronic obstructive pulmonary disease: a discrete choice experiment in the UK, USA and Germany. Int J Chron Obstruct Pulmon Dis. 2020;15:595-604. https://doi. org/10.2147/COPD.S221980.

37. Lloyd A, Doyle S, Dewilde S, Turk F. Preferences and utilities for the symptoms of moderate to severe allergic asthma. Eur J Health Econ. 2008;9(3):275-84. https://doi.org/10.1007/ s10198-007-0075-0.

38. Lloyd A, McIntosh E, Rabe KF, Williams A. Patient preferences for asthma therapy: a discrete choice experiment. Prim Care Respir J. 2007;16(4):241-8. https://doi.org/10.3132/pcrj.2007. 00052.

39. Lloyd A, McIntosh E, Williams AE, Kaptein A, Rabe KF. How does patients' quality of life guide their preferences regarding aspects of asthma therapy? A patient-preference study using discrete-choice experiment methodology. Patient. 2008;1(4):309-16. https://doi.org/10.2165/01312067-200801040-00012.

40. McKenzie L, Cairns J, Osman L. Symptom-based outcome measures for asthma: the use of discrete choice methods to assess patient preferences. Health Policy. 2001;57(3):193-204. https:// doi.org/10.1016/s0168-8510(01)00128-2.

41. McTaggart-Cowan HM, Shi P, Fitzgerald JM, Anis AH, Kopec JA, Bai TR, et al. An evaluation of patients' willingness to trade symptom-free days for asthma-related treatment risks: a discrete choice experiment. J Asthma. 2008;45(8):630-8. https://doi.org/ $10.1080 / 02770900802126990$.
42. Molimard M, Colthorpe P. Inhaler devices for chronic obstructive pulmonary disease: insights from patients and healthcare practitioners. J Aerosol Med Pulm Drug Deliv. 2015;28(3):219-28. https://doi.org/10.1089/jamp.2014.1142.

43. Naik-Panvelkar P, Armour C, Rose J, Saini B. Patients' value of asthma services in Australian pharmacies: the way ahead for asthma care. J Asthma. 2012;49(3):310-6. https://doi.org/10. 3109/02770903.2012.658130.

44. Naik-Panvelkar P, Armour C, Rose JM, Saini B. Patient preferences for community pharmacy asthma services: a discrete choice experiment. Pharmacoeconomics. 2012;30(10):961-76. https:// doi.org/10.2165/11594350-000000000-00000.

45. O'Conor RM, Blomquist GC. Measurement of consumer-patient preferences using a hybrid contingent valuation method. J Health Econ. 1997;16(6):667-83. https://doi.org/10.1016/s01676296(97)80198-1.

46. Osman LM, McKenzie L, Cairns J, Friend JA, Godden DJ, Legge JS, et al. Patient weighting of importance of asthma symptoms. Thorax. 2001;56(2):138-42. https://doi.org/10.1136/thorax.56.2. 138.

47. Pisa G, Freytag S, Schandry R. Chronic obstructive pulmonary disease (COPD) patients' disease-related preferences: a study using conjoint analysis. Patient. 2013;6(2):93-101. https://doi. org/10.1007/s40271-013-0007-2.

48. Ratcliffe J, Van Haselen R, Buxton M, Hardy K, Colehan J, Partridge M. Assessing patients' preferences for characteristics associated with homeopathic and conventional treatment of asthma: a conjoint analysis study. Thorax. 2002;57(6):503-8. https://doi. org/10.1136/thorax.57.6.503.

49. Svedsater H, Leather D, Robinson T, Doll H, Nafees B, Bradshaw L. Evaluation and quantification of treatment preferences for patients with asthma or COPD using discrete choice experiment surveys. Respir Med. 2017;132:76-83. https://doi.org/10.1016/j. rmed.2017.09.010.

50. Walzer S. What do parents want from their child's asthma treatment? Ther Clin Risk Manag. 2007;3(1):167-75. https://doi.org/ 10.2147/tcrm.2007.3.1.167.

51. Walzer S, Zweifel P. Willingness-to-pay for caregivers of children with asthma or wheezing conditions. Ther Clin Risk Manag. 2007;3(1):157-65. https://doi.org/10.2147/tcrm.2007.3.1.157.

52. Tervonen T, Martinez FJ, Hanania NA, Heidenreich S, Eudicone JM, Gilbert I. Dual-combination maintenance inhaler preferences in asthma and chronic obstructive pulmonary disease: a patientcentered benefit-risk assessment. Respir Med. 2020;176: 106278. https://doi.org/10.1016/j.rmed.2020.106278.

53. Goossens LM, Utens CM, Smeenk FW, Donkers B, van Schayck OC, Rutten-van Molken MP. Should I stay or should I go home? A latent class analysis of a discrete choice experiment on hospitalat-home. Value Health. 2014;17(5):588-96. https://doi.org/10. 1016/j.jval.2014.05.004.

54. Page MJ, McKenzie JE, Bossuyt PM, Boutron I, Hoffmann TC, Mulrow CD, et al. The PRISMA 2020 statement: an updated guideline for reporting systematic reviews. BMJ. 2021;372: n71. https://doi.org/10.1136/bmj.n71.

55. Lancsar E, Savage E. Deriving welfare measures from discrete choice experiments: inconsistency between current methods and random utility and welfare theory. Health Econ. 2004;13(9):9017. https://doi.org/10.1002/hec.870.

56. Mohamed AF, Hauber AB, Johnson FR, Coon CD. Patient preferences and linear scoring rules for patient-reported outcomes. Patient. 2010;3(4):217-27. https://doi.org/10.2165/11537880000000000-00000.

57. Rowen D, Brazier J, Van Hout B. A comparison of methods for converting DCE values onto the full health-dead QALY scale. Med Decis Making. 2015;35(3):328-40. https://doi.org/10.1177/ 0272989X14559542. 
58. Tervonen T, Hawken N, Hanania NA, Martinez FJ, Heidenreich $S$, Gilbert I. Maintenance inhaler therapy preferences of patients with asthma or chronic obstructive pulmonary disease: a discrete choice experiment. Thorax. 2020;75(9):735-43. https://doi.org/ 10.1136/thoraxjnl-2019-213974.

59. Fardet L, Kassar A, Cabane J, Flahault A. Corticosteroid-induced adverse events in adults: frequency, screening and prevention. Drug Saf. 2007;30(10):861-81. https://doi.org/10.2165/00002 018-200730100-00005.

60. Bloechliger M, Reinau D, Spoendlin J, Chang SC, Kuhlbusch K, Heaney LG, et al. Adverse events profile of oral corticosteroids among asthma patients in the UK: cohort study with a nested case-control analysis. Respir Res. 2018;19(1):75. https://doi.org/ 10.1186/s12931-018-0742-y.

61. Al Efraij K, Johnson KM, Wiebe D, Sadatsafavi M, FitzGerald JM. A systematic review of the adverse events and economic impact associated with oral corticosteroids in asthma. J Asthma. 2019;56(12):1334-46. https://doi.org/10.1080/02770903.2018. 1539100 .

62. Zazzali JL, Broder MS, Omachi TA, Chang E, Sun GH, Raimundo K. Risk of corticosteroid-related adverse events in asthma patients with high oral corticosteroid use. Allergy Asthma Proc. 2015;36(4):268-74. https://doi.org/10.2500/aap.2015.36.3863.

63. Food and Drug Administration. Product Approval InformationLicensing Action-Omalizumab. 2003. https://www.accessdata. fda.gov/drugsatfda_docs/appletter/2003/omalgen062003L.htm. Accessed 27 Dec 2020.

64. McGregor MC, Krings JG, Nair P, Castro M. Role of biologics in asthma. Am J Respir Crit Care Med. 2019;199(4):433-45. https:// doi.org/10.1164/rccm.201810-1944CI.

65. Wechsler ME. Current and emerging biologic therapies for asthma and COPD. Respir Care. 2018;63(6):699-707. https://doi.org/10. 4187/respcare.06322.
66. Trapero-Bertran M, Rodriguez-Martin B, Lopez-Bastida J. What attributes should be included in a discrete choice experiment related to health technologies? A systematic literature review. PLoS ONE. 2019;14(7): e0219905. https://doi.org/10.1371/journ al.pone.0219905.

67. Restrepo RD, Alvarez MT, Wittnebel LD, Sorenson H, Wettstein $\mathrm{R}$, Vines DL, et al. Medication adherence issues in patients treated for COPD. Int J Chron Obstruct Pulmon Dis. 2008;3(3):371-84. https://doi.org/10.2147/copd.s3036.

68. Engelkes M, Janssens HM, de Jongste JC, Sturkenboom MC, Verhamme KM. Medication adherence and the risk of severe asthma exacerbations: a systematic review. Eur Respir J. 2015;45(2):396407. https://doi.org/10.1183/09031936.00075614.

69. Bender BG, Bender SE. Patient-identified barriers to asthma treatment adherence: responses to interviews, focus groups, and questionnaires. Immunol Allergy Clin North Am. 2005;25(1):107-30. https://doi.org/10.1016/j.iac.2004.09.005.

70. Horne R. Compliance, adherence, and concordance: implications for asthma treatment. Chest. 2006;130(1 Suppl):65S-72S. https:// doi.org/10.1378/chest.130.1_suppl.65S.

71. Al-Jahdali H, Ahmed A, Al-Harbi A, Khan M, Baharoon S, Bin Salih S, et al. Improper inhaler technique is associated with poor asthma control and frequent emergency department visits. Allergy Asthma Clin Immunol. 2013;9(1):8. https://doi.org/10.1186/ 1710-1492-9-8.

72. Gangemi A, Kim V, Criner G. Customer is always right: optimising inhaler design to fit patient preferences in obstructive lung disease. Thorax. 2020;75(9):711-2. https://doi.org/10.1136/thora xjnl-2020-215238.

73. Kløjgaard ME, Bech M, Søgaard R. Designing a stated choice experiment: the value of a qualitative process. J Choice Modell. 2012;5(2):1-8. 